\title{
Determinants of prelacteal feeding practice in Uganda; a population based cross-sectional study using Uganda demographic and health survey data
}

\author{
Ibrahim Isa Koire ${ }^{1}$, Ayla Acikgoz ${ }^{2 *}$, Turkan Gunay ${ }^{3}$ \\ 1. Central College Kawaala, Kampala, Uganda \\ 2. Vocational School of Health Services, Dokuz Eylul University, Izmir, Turkey \\ 3. Department of Public Health, School of Medicine, Dokuz Eylul University, Izmir, Turkey
}

*Corresponding Authors: Ayla Acikgoz; E-mail: ayla.acikgoz@deu.edu.tr

\begin{abstract}
Background
Abstract

Breastfeeding has well-established short-term and long-term health benefits for both the mother and infant. Initiating breastfeeding immediately after birth stimulates breast milk production. Prelacteal feeding (PLF) may result in late initiation of breastfeeding, and thus insufficient production of breast milk. This study aimed to identify the determinants of PLF among children under five years in Uganda.

Methods

This cross-sectional study was conducted using the data from the database of Uganda Demographic and Health Survey 2011. The data of 4,774 children/mothers were evaluated in this study.

Results

The prevalence of PLF was 40.3\%. The rate of PLF practice was found to be 2.15 times higher in women with moderate economic status and 2.02 times higher in women with high economic status compared to those who have low economic status. The rate of PLF practice was found to be 1.73 times higher in newborns delivered by an unskilled birth attendant and 4.35 times higher in newborns delivered with no birth attendant compared to those infants delivered by a skilled birth attendant. The ratio of PLF practice was found to be 2.49 times higher in multiple births. Mothers who initiated breastfeeding in the first 24 hours after birth had higher odds of PLF. No relationship was found between PLF practice with some sociodemographic characteristics of mother's (age, marital status, educational status, religion, residential location), maternal factors (number of children, antenatal and postnatal care attendance, place of delivery), and characteristics of the newborn infants (sex, type of delivery, birth order number) in the multivariate logistic regression analysis.

Conclusions

All mothers should be informed about the importance of initiation of breastfeeding immediately after delivery, the risks associated with PLF, the optimal practices for breastfeeding, and the presence of a skilled birth attendant at delivery.
\end{abstract}

Keywords: prelacteal feeding, newborn, infants, Uganda, breastfeeding, breast milk.

\section{Introduction}

Appropriate feeding of infants is important for healthy growth and development. Breast milk contains all the nutritional requirements for infants below six months of age, except vitamin $\mathrm{D}^{1}$. The World Health Organization (WHO) recommends that breastfeeding should be started within one hour after birth and infants should be exclusively breastfed for the first six months ${ }^{2}$. Exclusive breastfeeding (EBF) means that the infant is fed only breast milk for six months of life; any additional solids or liquids, including water, are not given ${ }^{1,2}$.

Breastfeeding has well-established short-term and long-term health benefits for both the mother and infant, particularly for the reduction of morbidity and mortality due to infectious diseases such as gastroenteritis or pneumonia in first two years of life and the risk of obesity in childhood ${ }^{3,4}$. Initiating breastfeeding immediately after birth stimulates breast milk production ${ }^{1}$. Thus, exclusive breastfeeding results in abundant milk production ${ }^{2}$.

Providing any food or liquid, including water, other than breast milk to a newborn during the first three days of birth is defined as prelacteal feeding (PLF) ${ }^{5}$. It may result in late initiation of breastfeeding, insufficient production of breast milk, and a decrease of the immunological benefits of colostrum, which contains a high proportion of antibacterial agents ${ }^{6}$. Since gut is immature in the early days of newborn ${ }^{7}$, prelacteal feeds, which are contaminated easily, may cause infections which may lead to death ${ }^{8}$.

Using data from the most recent Demographic and Health Survey (2000-2013) for 57 countries, Oakley et al. have found that $51 \%$ of the infants receive PLF. The prevalence of prelacteal feeding in these countries ranges from 3 to $97 \%$. Overall, $39 \%$ of children receive a prelacteal feed in Sub-Saharan Africa'. However, PLF rates differ among countries. Only $3 \%$ of children receive prelacteal feed in Malawi, while in Ivory Coast the rate of PLF is $67 \%{ }^{10}$. The determinants of PLF are multifactorial and may differ among countries $^{10-13}$. Sociodemographic characteristics of mothers', characteristics of the infants', antenatal factors, and postnatal factors are significantly associated with the introduction of prelacteal feeds. For example, younger mothers may lack the required experience to practice appropriate infant feeding ${ }^{10,12}$. High educational level of the mother can make them more aware of recommendations regarding PLF ${ }^{10,12,13}$. 
Table 1: The association between sociodemographic characteristics of mother and prelacteal feeding

\begin{tabular}{|c|c|c|c|c|c|c|c|}
\hline \multirow{3}{*}{\multicolumn{2}{|c|}{ Characteristics }} & \multirow{4}{*}{$\begin{array}{l}\text { Total } \\
\text { N (\%) } \\
363(7.6)\end{array}$} & \multicolumn{4}{|c|}{ Prelacteal feeding } & \multirow{4}{*}{$\begin{array}{l}\mathrm{p} \\
0.019\end{array}$} \\
\hline & & & \multicolumn{2}{|c|}{ Yes } & \multicolumn{2}{|c|}{ No } & \\
\hline & & & $\mathbf{n}$ & $\%$ & $\mathbf{n}$ & $\%$ & \\
\hline \multirow{7}{*}{ Age } & $15-19$ & & 168 & 46,3 & 195 & 53,7 & \\
\hline & $20-24$ & $1154(24.2)$ & 465 & 40.3 & 689 & 59.7 & \\
\hline & $25-29$ & $1331(27,9)$ & 509 & 38,2 & 822 & 61.8 & \\
\hline & $30-34$ & $847(17.7)$ & 319 & 37.7 & 528 & 62.3 & \\
\hline & $35-39$ & $664(13.9)$ & 293 & 44,1 & 371 & 55,9 & \\
\hline & $40-44$ & $310(6.5)$ & 122 & 39,4 & 188 & 60.6 & \\
\hline & $45-49$ & $105(2.2)$ & 47 & 44.8 & 58 & 55.2 & \\
\hline \multirow[t]{4}{*}{ Education } & Illiterate & $837(17.5)$ & 268 & 32.0 & 569 & 68.0 & \multirow[t]{4}{*}{$<0.001$} \\
\hline & Primary school & $2774(58.2)$ & 1136 & 41.0 & 1638 & 59.0 & \\
\hline & $\begin{array}{l}\text { Secondary/high } \\
\text { school }\end{array}$ & $937(19.6)$ & 429 & 45.8 & 508 & 54.2 & \\
\hline & University & $226(4.7)$ & 90 & 39.8 & 136 & 60.2 & \\
\hline \multirow{2}{*}{$\begin{array}{l}\text { Marital } \\
\text { status }\end{array}$} & Not married & $750(15.7)$ & 338 & 45.1 & 412 & 54.9 & \multirow[t]{2}{*}{0.004} \\
\hline & Married & $4023(84.3)$ & 1585 & 39.4 & 2438 & 60.6 & \\
\hline \multirow{2}{*}{$\begin{array}{l}\text { Residential } \\
\text { location }\end{array}$} & Urban & $1143(23,9)$ & 503 & 44,0 & 640 & 56,0 & \multirow[t]{2}{*}{0.003} \\
\hline & Rural & $3631(76.1)$ & 1420 & 39.1 & 2211 & 60.9 & \\
\hline \multirow{3}{*}{$\begin{array}{l}\text { Economic } \\
\text { status }\end{array}$} & Low & $2074(43,5)$ & 710 & 34,2 & 1364 & 65,8 & \multirow[t]{3}{*}{$<0.001$} \\
\hline & Middle & $816(17.1)$ & 368 & 45.1 & 448 & 54.9 & \\
\hline & High & $1884(39.4)$ & 845 & 44.9 & 1039 & 55.1 & \\
\hline \multirow{3}{*}{$\begin{array}{l}\text { Mother's } \\
\text { religion }\end{array}$} & Christian & $4061(85,1)$ & 1583 & 39,0 & 2478 & 61,0 & \multirow[t]{3}{*}{$<0.001$} \\
\hline & Muslim & $664(13,9)$ & 315 & 47,4 & 349 & 52,6 & \\
\hline & Others & $49(1.0)$ & 25 & 51,0 & 24 & 49,0 & \\
\hline \multirow{3}{*}{$\begin{array}{l}\text { Number of } \\
\text { children }\end{array}$} & $1-2$ & $1753(37.0)$ & 736 & 42,0 & 1017 & 58,0 & \multirow[t]{3}{*}{0.038} \\
\hline & $3-4$ & $1388(29.2)$ & 521 & 37.3 & 867 & 62.5 & \\
\hline & $\geq 5$ & $1603(33.8)$ & 652 & 40.7 & 951 & 59.3 & \\
\hline
\end{tabular}

*column percentages, "row percentages

High economic status may provide easy access to other expensive breastfeeding alternatives ${ }^{10,12,13}$. Mothers' concerns regarding antibiotics that are taken during cesarean and pain that is caused by cesarean may cause a high rate of $\mathrm{PLF}^{10}$. To reduce PLF practice, culturally sensitive programs should be developed ${ }^{14}$. Therefore, the determinants of prelacteal feeding should be defined for each country, separately.

PLF is a widespread practice in Uganda. The Uganda Demographic and Health Survey (UDHS) 2011 showed that the prevalence of PLF among the children born in the last two years (2010-2011) was 41\% in Uganda ${ }^{5}$. In the literature search conducted in Pubmed, no study examining the determinants of PLF was found in Uganda, except for the study by Wamani et al. in $2002^{15}$. In this study that was conducted in a rural area with 720 child/mother couples, few sociodemographic variables were examined and mothers with higher education levels were found to be more likely to give prelecteals ${ }^{15}$. Comprehensive analysis of factors influencing PLF is essential to develop an intervention program to promote the early initiation of breastfeeding and EBF in Uganda. Therefore, this study aims to identify the determinants of PLF among children under five years using a dataset from the UDHS 2011.

\section{Methods}

Study setting and ethics 
Table 2: The association between maternal utilization of healthcare services and prelacteal feeding practice

\begin{tabular}{|c|c|c|c|c|c|c|c|}
\hline \multirow{3}{*}{\multicolumn{2}{|c|}{ Characteristics }} & \multirow{4}{*}{$\begin{array}{l}\text { Total } \\
\text { N }(\%)^{*} \\
4514(96.3)\end{array}$} & \multicolumn{4}{|c|}{ Prelacteal feeding } & \multirow{3}{*}{$\mathbf{p}$} \\
\hline & & & \multicolumn{2}{|c|}{ Yes } & \multicolumn{2}{|c|}{ No } & \\
\hline & & & $\mathbf{n}$ & $\%$ & $\mathbf{n}$ & $\%$ & \\
\hline \multirow{2}{*}{$\begin{array}{l}\text { Antenatal } \\
\text { care } \\
\text { attendance }\end{array}$} & Yes & & 1805 & 40.0 & 2709 & 60.0 & \multirow[t]{2}{*}{0.447} \\
\hline & No & $175(3.7)$ & 75 & 42.9 & 100 & 57.1 & \\
\hline \multirow[t]{3}{*}{$\begin{array}{l}\text { Place of } \\
\text { delivery }\end{array}$} & $\begin{array}{l}\text { Health } \\
\text { facility }\end{array}$ & $1792(37.5)$ & 744 & 41.5 & 1048 & 58.5 & \multirow[t]{3}{*}{0,40 I } \\
\hline & At home & $2934(61.5)$ & 1160 & 39.5 & 1774 & 60.5 & \\
\hline & Other place & $48(1.0)$ & 19 & 39.6 & 29 & 60.4 & \\
\hline \multirow{3}{*}{$\begin{array}{l}\text { Birth } \\
\text { assistant at } \\
\text { delivery }\end{array}$} & $\begin{array}{l}\text { No birth } \\
\text { attendant }\end{array}$ & $290(6.1)$ & 143 & 49.3 & 147 & 50.7 & \multirow[t]{3}{*}{0.005} \\
\hline & $\begin{array}{l}\text { Unskilled } \\
\text { birth } \\
\text { attendant }\end{array}$ & $1468(30,7)$ & 582 & 39.6 & 886 & 60.4 & \\
\hline & $\begin{array}{l}\text { Skilled birth } \\
\text { attendant }\end{array}$ & $3016(63.2)$ & 1198 & 39.7 & 1818 & 60.3 & \\
\hline \multirow{2}{*}{$\begin{array}{l}\text { Postnatal } \\
\text { care } \\
\text { attendance }\end{array}$} & Yes & $1001(35.2)$ & 409 & 40.9 & 592 & 59.1 & \multirow[t]{2}{*}{0.945} \\
\hline & No & $1844(64.8)$ & 751 & 40.7 & 1093 & 59.3 & \\
\hline
\end{tabular}

*column percentages, ${ }^{*}$ row percentages

This cross-sectional study was conducted using the data from the database of UDHS 2011. Authorization to use the data was given by The Demographic and Health Surveys Program (Date: 14 ${ }^{\text {th }}$ Dec. 2015). The UDHS 2011 was the fifth in the series of Demographic and Health Surveys conducted in Uganda ${ }^{5}$. Ethical approval was obtained from the Non-interventional Clinical Research Ethics Committee of Dokuz Eylul University, Izmir, Turkey (Decision No. 2016/33-28).

\section{Study sample}

The UDHS 2011 was designed to provide population and health indicator estimates for the country as a whole and for urban and rural areas separately. Estimates were reported for the 10 regions of Uganda. The UDHS 2011 was conducted on a stratified sample. In total, a representative sample of 10,086 households (2,977 in urban areas and 7,109 in rural areas) was selected for the UDHS $2011^{5}$. Details of sampling technique, selection of households, questionnaire and validation procedure were published in the UDHS 2011 report ${ }^{5}$.

The data of UDHS 2011 were collected between June and December 2011. A total of 9,247 women aged 15-49 years (urban $=2,805$ and rural $=6,442$ women) were identified as eligible for individual interviews, and 94 percent $(8,674$ women) were successfully interviewed ${ }^{5}$.

Analysis for our study was restricted among last-born children who were born in the five years preceding the survey. In our study, the total sample size was 7,581. Because their PLF data were not recorded in the database, 2,807 mothers were excluded from our study. Therefore, the data of 4,774 children/mothers were evaluated in this study.

\section{Outcome variable}

In the UDHS 2011 women questionnaire, mothers were asked: "In the first three days after delivery, was (NAME) given anything to drink other than breast milk?". "What was (NAME) given to drink? (Options: milk (other than breast milk), plain water, sugar or glucose water, gripe water, sugarsalt-water solution, fruit juice, infant formula, tea/infusions, honey, coffee, and other)" "5. In this study, PLF, the dependent variable, was defined as providing any food or liquid other than breast milk to a newborn during the first three days after delivery. The independent variables were chosen based on previous studies ${ }^{12,13,16-26}$ and grouped into four categories: sociodemographic characteristics of mothers', characteristics of the infants', antenatal factors, and postnatal factors.

\section{Statistical analysis}

Continuous variables were presented as mean and standard deviation whereas categorical variables were expressed as number and frequency. The association between the categorical independent variables and PLF was analyzed by using a chi-square test. The variables that were found statistically significant in the chi-square test and variables based on previous literature were included in the logistic regression analysis. A p value higher than 0.05 was considered statistically significant. Statistical analyses were performed using the Statistical Package for Social Sciences, Version 20.0 (IBM Corp., Armonk, NY, USA). 
Table 3: The association between characteristics of the newborn infants and prelacteal feeding

\begin{tabular}{|c|c|c|c|c|c|c|c|}
\hline \multirow{3}{*}{\multicolumn{2}{|c|}{ Characteristics of infant }} & \multirow{4}{*}{$\begin{array}{l}\text { Total } \\
\text { N }(\%)^{*} \\
2402(50,3)\end{array}$} & \multicolumn{4}{|c|}{ Prelacteal feeding } & \multirow{4}{*}{$\begin{array}{l}\mathbf{p} \\
0.276\end{array}$} \\
\hline & & & \multicolumn{2}{|c|}{ Yes } & \multirow{2}{*}{\multicolumn{2}{|c|}{ n $\quad \mathrm{No}^{\mathrm{n}}{ }^{\ddagger}$}} & \\
\hline & & & \multicolumn{2}{|c|}{ n $\quad \%$} & & & \\
\hline \multirow[t]{2}{*}{ Sex } & Male & & 986 & 41,0 & 1416 & 59,0 & \\
\hline & Female & $2372(49,7)$ & 937 & 39.5 & 1435 & 60,5 & \\
\hline \multirow[t]{2}{*}{$\begin{array}{l}\text { Weight of infant } \\
\text { at birth (gram) }\end{array}$} & $\begin{array}{l}\text { Small } \\
(<2500)\end{array}$ & $247(9.4)$ & 95 & 38.5 & 152 & 61.5 & \multirow[t]{2}{*}{0.914} \\
\hline & $\begin{array}{l}\text { Average- } \\
\text { Large } \\
(2500-6000)\end{array}$ & $2373(90.6)$ & 921 & 38.8 & 1452 & 61.2 & \\
\hline \multirow[t]{2}{*}{ Type of delivery } & $\begin{array}{l}\text { Caesarean } \\
\text { section }\end{array}$ & $318(6.7)$ & 179 & 56.3 & 139 & 43.7 & \multirow[t]{2}{*}{$<0.001$} \\
\hline & Normal birth & $4456(93,3)$ & 1744 & 39.1 & 2412 & 60,9 & \\
\hline \multirow[t]{2}{*}{ Type of birth } & $\begin{array}{l}\text { Multiple } \\
\text { births }\end{array}$ & $85(1.8)$ & 47 & 55.3 & 38 & 44.7 & \multirow[t]{2}{*}{0.004} \\
\hline & Single birth & $4689(98,2)$ & 1876 & 40,0 & 2813 & 60,0 & \\
\hline \multirow{4}{*}{$\begin{array}{l}\text { Birth order } \\
\text { number }\end{array}$} & $1^{\text {nd }}$ born & $789(16.5)$ & 362 & 45.9 & 427 & 54.1 & \multirow[t]{4}{*}{0.001} \\
\hline & $2^{\text {nd }}$ born & $808(16.9)$ & 315 & 39.0 & 493 & 61.0 & \\
\hline & $3^{\text {rd }}$ born & $652(13.7)$ & 236 & 36.2 & 416 & 63.8 & \\
\hline & $\geq 4^{\text {th }}$ born & $2525(52.9)$ & 1010 & 40.0 & 1515 & 60.0 & \\
\hline \multirow[t]{3}{*}{$\begin{array}{l}\text { The timing of } \\
\text { breastfeeding } \\
\text { initiation }\end{array}$} & $\begin{array}{l}\text { The first } 24 \\
\text { hours at any } \\
\text { time }\end{array}$ & $262(7.8)$ & 180 & 68.7 & 82 & 31.3 & \multirow[t]{3}{*}{$<0.001$} \\
\hline & $\begin{array}{l}\text { Within } 1^{\text {st }} \\
\text { hour }\end{array}$ & $668(19.9)$ & 251 & 37.6 & 417 & 62.4 & \\
\hline & Immediately & $2432(72,3)$ & 758 & 31,2 & 1674 & 68,8 & \\
\hline
\end{tabular}

\section{Results}

Prevalence of prelacteal feeding according to sociodemographic characteristics of mothers and newborn infants

A total of 4774 mother-child pairs participated in our study. A total of 1923 (40.3\%) mothers reported providing prelacteal feeds to their newborn infants. The average age of the mothers was $28.7 \pm 7.1$ (mean $\pm \mathrm{SD}$ ) years. Results of the chi-square tests to determine the association of factors between sociodemographic characteristics of mothers' and prelacteal feeding are shown in Table 1. In chi-square analysis, the highest rate of PLF was observed among mothers who are between 15-19 years old, who have secondary/high school education, who are not married, who live in urban areas, who have higher economic status, who have religions other than Christianity and Islam, and who have one and/or two children $(p<0.05)$, (Table 1). The frequency of infants with prelacteal feeds was also higher among in women with no birth attendant at delivery $(\mathrm{p}<0.05)$, (Table 2).
In the chi-square analysis, we found that type of delivery (cesarean section), multiple births, birth order number (first birth order), and timing of breastfeeding initiation (first 24 hours) were significantly associated with prelacteal feeding practice $(\mathrm{p}<0.05)$, (Table 3$)$.

\section{Factors associated with prelacteal feeding}

In this study, the variables found to be significant in the chi-square analysis and variables based on previous literature were examined together in the multivariate logistic regression model. The rate of PLF practice was found to be 2.15 times (OR: 2.15, 95\% CI=1.38-3.36) higher in women with moderate economic status compared to those who have low economic status. Similarly, the rate of PLF practice was found to be 2.02 times (OR: 2.02, 95\% CI=1.44-2.82) higher in women with high economic status compared to those who have low economic status. Another significant factor that influenced PLF was the presence of a birth assistant at delivery. The rate of PLF practice was found to be 1.73 times higher in newborns who delivered by an unskilled birth 
Table 4: Multivariate logistic regression analysis prelacteal feeding practice and associated factors

\begin{tabular}{|c|c|c|c|c|c|c|}
\hline \multicolumn{2}{|l|}{ Characteristics } & \multirow{2}{*}{$\begin{array}{l}\begin{array}{l}\text { Crude } \\
\text { Odds } \\
\text { Ratio }\end{array} \\
1.00 \\
\text { (ref.) }\end{array}$} & \multirow[t]{2}{*}{$95 \%$ CI } & \multirow{2}{*}{$\begin{array}{l}\text { Adj. } \\
\text { Odds } \\
\text { Ratio } t \\
1.00 \\
\text { (ref.) }\end{array}$} & \multirow[t]{2}{*}{$95 \%$ CI } & \multirow[t]{2}{*}{ p } \\
\hline \multirow[t]{3}{*}{$\begin{array}{l}\text { Economic } \\
\text { status }\end{array}$} & Low & & & & & \\
\hline & Middle & 1.58 & $1.34-1.86$ & 2.15 & $1.38-3.36$ & 0.001 \\
\hline & High & 1.56 & $1.37-1.78$ & 2.02 & $1.44-2.82$ & $<0.001$ \\
\hline \multirow[t]{3}{*}{$\begin{array}{l}\text { Birth assistant } \\
\text { at delivery }\end{array}$} & $\begin{array}{l}\text { Skilled birth } \\
\text { attendant }\end{array}$ & $\begin{array}{l}1,00 \\
\text { (ref.) }\end{array}$ & & $\begin{array}{l}1,00 \\
\text { (ref.) }\end{array}$ & & \\
\hline & $\begin{array}{l}\text { Unskilled birth } \\
\text { attendant }\end{array}$ & 1.00 & $0.88-1.13$ & 1.73 & $1.04-2.88$ & 0.035 \\
\hline & $\begin{array}{l}\text { No birth } \\
\text { attendant }\end{array}$ & 1.48 & $1.16-1.88$ & 4.35 & $1.01-18.67$ & 0.048 \\
\hline \multirow[t]{2}{*}{ Type of birth } & Single birth & $\begin{array}{l}1,00 \\
\text { (ref.) }\end{array}$ & & $\begin{array}{l}1,00 \\
\text { (ref.) }\end{array}$ & & \\
\hline & Multiple births & 1.85 & $1.21-2.87$ & 2.49 & $1.04-5.94$ & 0.040 \\
\hline \multirow{3}{*}{$\begin{array}{l}\text { The timing of } \\
\text { breastfeeding } \\
\text { initiation }\end{array}$} & Immediately & $\begin{array}{l}1.00 \\
\text { (ref.) }\end{array}$ & & $\begin{array}{l}1.00 \\
\text { (ref.) }\end{array}$ & & \\
\hline & Within $1^{\text {st }}$ hour & 1.33 & $1.11-1.59$ & 1.34 & $0.96-1.87$ & 0.088 \\
\hline & $\begin{array}{l}\text { The first } 24 \text { hours } \\
\text { at any time }\end{array}$ & 4.85 & $3.69-6.40$ & 5.08 & $2.98-8.64$ & $<0.001$ \\
\hline
\end{tabular}

$\uparrow$ Adjusted according to sociodemographic characteristics of mother (age, marital status, educational status, economic status, religion, residential location), maternal factors (number of children, antenatal and postnatal care attendance, place of delivery, birth assistant history at delivery) and the newborn infants characteristics (sex, type of delivery, type of birth, birth order number, timing of breastfeeding initiation).

attendant, and 4.35 times higher in newborns who delivered with no birth attendant (OR: 1.73, 95\% CI=1.04-2.88 and OR: $4.35,95 \% \mathrm{CI}=1.01-18.67$, respectively) compared to those delivered by a skilled birth attendant. The ratio of PLF practice was found to be 2.49 times higher in mothers who had multiple births (OR: 2.49, 95\% CI=1.04-5.94) compared to those who gave birth to a single baby. In addition, mothers who initiated breastfeeding in the first 24 hours after birth had higher odds of PLF (OR: 5.08, 95\% CI=2.98-8.64) compared to those who initiated breastfeeding immediately after delivery (Table 4).

No relationship was found between prelacteal feeding practice and some sociodemographic characteristics of mother's (age, marital status, educational status, religion, residential location), maternal factors (number of children, antenatal and postnatal care attendance, place of delivery), and characteristics of the newborn infants (sex, type of delivery, birth order number) in the multivariate logistic regression analysis.

\section{Discussion}

This study investigated the prevalence of PLF practice in children under five and associated factors in Uganda. In this study, about two-five of mothers reported that they provided prelacteal feeds to their newborn infants. The rate of PLF practice was higher in mothers who have high and moderate economic status, in newborns who delivered by an unskilled birth attendant, in newborns who delivered without a birth attendant, in multiple births, and in newborns who began breastfeeding in the first 24 hours after delivery.

We found that prevalence of PLF was $40.3 \%$ in Uganda. Although it is known that PLF has a negative effect on the growth and development of infants, the prevalence of PLF is higher in Uganda. Our observed prevalence was higher than the overall prevalence of PLF in twenty-two sub-Saharan African (SSA) countries which was reported to be $32.2 \%{ }^{10}$. The prevalence of PLF in African countries varies from $2.5 \%$ to $85.2^{10,12,16-22}$. The prevalence of PLF in Asian countries has been reported as $73.3 \%$ in Vietnam ${ }^{23}, 49.8 \%$ and $42.7 \%$ in India ${ }^{24,25}, 26.5 \%$ in $\mathrm{Nepal}^{13}$, and $12.3 \%$ in Timor-Leste ${ }^{26}$. Using data from the most recent Demographic and Health Survey (2000-2013) for 57 countries, Oakley et al. found that prevalence of PLF was $51 \%$. The differences in the prevalence of PLF among countries may be attributed to differences in culture and local beliefs and availability of an adequate level of maternal and health service. Misconception towards breastfeeding among Vietnamese mothers may cause to high PLF rates ${ }^{23}$. Decreased suckling time of an infant and prelacteal feeding can result in decreased breast milk supply. The decrease in breast milk creates a vicious circle by encouraging the mother to PLF. Therefore, breastfeeding practices may explain different rates of PLF between countries. For example, while the PLF rate is 3\% in Malawi, where the rate of exclusive breastfeeding is 
$71 \%{ }^{27}$, the rate of PLF is $73 \%$ in Vietnam, where the rate of exclusive breastfeeding is $20 \%{ }^{23}$.

In the chi-square analysis, we found that PLF practice associated with some sociodemographic characteristics of mother's (age, educational status, marital status, residential location, economic status, religion of mother), maternal factors (birth assistant at delivery, number of children), and characteristics of the newborn infants (type of delivery, multiple births, birth order number, timing of breastfeeding initiation). In this study, the variables found to be significant in the chi-square analysis were examined together in the multivariate logistic regression model. Some variables that were found to be significant in the chi-square analysis were not significant in the logistic regression analysis.

In the logistic regression analysis, we found that economic status, the presence of a birth assistant at delivery, multiple births, and the timing of breastfeeding initiation were significant predictors affecting PLF. Consistent with the results of a recent pooled analysis from Demographic and Health Surveys in twenty-two SSA countries ${ }^{10}$, we found that mothers who have high and moderate economic status are more likely to give prelacteal feeds to infant. Our findings are also similar to other studies indicating that lower economic status has a protective effect on PLF ${ }^{13,23-26}$. A possible explanation is that mothers who have lower economic status may have less access to the expensive prelacteal feeds and therefore exclusive breastfeeding is the only alternative available to them ${ }^{10,23,24}$. In contrast to our study and previous studies $^{13,23-26}$, two studies from Nigeria reported that high socioeconomic status has a protective effect on PLF ${ }^{12,17}$. These contradictory results among countries could be attributed to differences in population characteristics.

Maternal utilization of healthcare services can play an important role on the early breastfeeding practice ${ }^{1}$. We found that mothers who had an unskilled birth attendant at delivery were approximately 1.7 times more likely to practice PLF, while women who had no birth attendant at delivery were approximately 4.4 times more likely to practice PLF. However, we could not find a relationship between PLF with the place of delivery, mothers who had antenatal care attendance and postnatal care attendance in the multivariate logistic regression analysis. Oakley et al. reported that the presence of a skilled birth attendant is positively correlated with favorable breastfeeding practices in Middle East/ Europe, Latin America, particularly in SSA and Asia. PLF practice was higher among deliveries without skilled birth attendant except Latin America?. Similarly, studies have found lower prevalence of PLF in mothers who have an skilled birth attendant at delivery ${ }^{10,15,17,19}$. When birth occurs without a skilled birth attendant, the most significant source of breastfeeding information comes from family and friends who may advise PLF $\mathrm{PL}^{12,19,22,23}$. Inconsistent with our study, some studies have demonstrated a strong link between PLF practice and mothers who have antenatal and postnatal care visits ${ }^{12,16,17,19}$. As a result, the presence of a skilled birth attendant is an important factor in terms of avoiding from PLF. Mothers who have no skilled birth attendant may not receive health information on optimal breastfeeding practices, which could be a likely reason for the high odds of PLF observed in these mothers. Within this scope, breastfeeding counseling should be integrated into routine prenatal and postnatal care in Uganda.

It may be difficult to breastfeed the twin infants at the same time $^{28}$. We found that multiple births were significantly associated with higher PLF practice compared to those who gave birth to a single baby in Uganda. This finding is in agreement with another study conducted in Nigeria using the 2013 demographic and health survey data ${ }^{17}$. Due to the fact that multiple births are likely to be difficult, it is suggested that breastfeeding after birth may be more problematic. The information and support from health staff are the most critical factors associated with the success of breastfeeding in mothers delivering multiple births ${ }^{28}$.

The strongest finding of our study was that PLF practice was more common in mothers who initiated breastfeeding in the first 24 hours after birth as compared to those who initiated breastfeeding immediately after birth. This finding is in agreement with other studies conducted in India ${ }^{24}$ and Ethiopia ${ }^{18}$. Moreover, a community based cross-sectional study conducted in the Ethiopia has demonstrated that PLF practice is nine times more likely in mothers who discard colostrum, compared to mothers who give colostrum to their infant ${ }^{19}$. In another study, similarly, the presence of PLF has been found to be five times more likely among mothers who discard the colostrum ${ }^{16}$. All mothers should be informed and supported about the importance of initiation of EBF practice immediately after delivery ${ }^{14}$. An intervention trial conducted in Burkina Faso, Uganda and South Africa has found that PLF practice is lower the women in the intervention group, receiving EBF counselling, than in the control group ${ }^{20}$.

The main strengths of this study were the collection of data by using a validated questionnaire and the use of an internationally validated study method. In addition, since response rate was high, this study may be considered a study representing the nation. Therefore, the findings are generalizable to the entire country. Moreover, this is the first study conducted in Uganda to describe the predictors associated with PLF. Despite these strengths, the current study has some limitations. First, the data set we used is cross-sectional, which limits the ability to show any causality. Second, since the data of study were collected through a questionnaire, it may be associated with the potential recall bias. Third, other unknown factors such as local beliefs and culture may have played a role as a confounding factor in the study. Fourth, our study was conducted using the data received from the database of UDHS 2011. The data of the article may seem to be outdated, because another report was published in 2016. As we mentioned in the Method section, we got permission to use the database in December 2015. At that date, UDHS 2016 data had not yet been shared. Accordingly, we think that it is important to publish the results of our study, since the last study on this subject in Uganda was conducted in 2002.

\section{Conclusions}

In Uganda, the prevalence of PLF was relatively high $(40.3 \%)$. Economic status of the mother, the presence of a birth assistant at delivery, multiple births, and timing of breastfeeding initiation were found to be associated with PLF. Improving the awareness of mothers on subjects such as the risks associated with PLF, the optimal practices for breastfeeding, and the presence of a skilled birth attendant at delivery is recommended for Uganda. During antenatal and postnatal care visits, all mothers should be informed about the importance of initiation of breastfeeding immediately after delivery. It is recommended to establish baby friendly hospitals for the promotion of mother and baby health in 
Uganda.

\section{Acknowledgements}

The authors would like to acknowledge Measure DHS for making available the UDHS 2011 data set for this study.

\section{Conflict of interest}

All authors declare that they have no competing interests related to this work.

\section{References}

1. World Health Organization. Infant and young child feeding: model chapter for textbooks for medical students and allied health professionals. Geneva: 2013.

2. emro.who.int [Internet]. World Health Organization (Eastern Mediterranean Regional Office) Exclusively breastfeed for 6 months. [cited 2021 Jul 04]. Available from: www.emro.who.int/nutrition/ breastfeeding/index.html

3. Gertosio C, Meazza C, Pagani S, Bozzola M. Breastfeeding and its gamut of benefits. Minerva Pediat. 2016;68(3):201-12.

4. Horta BL, Victora CG. Long-term effect of breastfeeding: a systematic review. World Health Organization. Geneva: 2013.

5. Uganda Bureau of Statistics (UBOS) and ICF International Inc. Uganda Demographic and Health Survey 2011. Kampala, Uganda: UBOS and Calverton, Maryland: ICF International Inc: 2012.

6. Clare DA, Catignani GL, Swaisgood HE. Biodefense properties of milk: the role of antimicrobial proteins and peptides. Curr Pharm Des. 2003;9(16):1239-55.

7. Basu S. Neonatal sepsis: the gut connection. Eur J Clin Microbiol Infect Dis. 2015; 34(2):215-22. doi:10.1007/s10096-014-2232-6

8. Hajeebhoy N, Nguyen PH, Mannava P, Nguyen TT, Mai LT. Suboptimal breastfeeding practices are associated with infant illness in Vietnam. Int Breastfeed J. 2014;9:12. doi:10.1186/1746-4358-9-12 eCollection 2014

9. Oakley L, Benova L, Macleod D, Lynch CA, Campbell OMR. Early breastfeeding practices: Descriptive analysis of recent Demographic and Health Surveys. Matern Child Nutr. 2018;14(2):e12535. doi:10.1111/ mcn. 12535

10. Berde AS, Ozcebe H. Risk factors for prelacteal feeding in subSaharan Africa:a multilevel analysis of population data from twentytwo countries. Public Health Nutr. 2017;20(11):1953-62. doi:10.1017/ S1368980017000659

11. Takele WW, Tariku A, Wagnew F, Ekubagewargies DK, Getinet W, Derseh L et al. Magnitude of prelacteal feeding practice and its association with place of birth in Ethiopia: a systematic review and meta-analysis, 2017. Arch Public Health. 2018;76:63. doi:10.1186/ s13690-018-0308-y

12. Agho KE, Ogeleka P, Ogbo FA, Ezeh OK, Eastwood J, Page A. Trends and predictors of prelacteal feeding practices in Nigeria (2003-2013). Nutrients. 2016;8(8):pii:E462. doi:10.3390/nu8080462

13. Khanal V, Adhikari M, Sauer K, Zhao Y. Factors associated with the introduction of prelacteal feeds in Nepal: findings from the Nepal Demographic and Health Survey 2011. Int Breastfeed J. 2013;8(1):9. doi:10.1186/1746-4358-8-9

14. World Health Organization, UNICEF. Planning guide for national implementation of the Global Strategy for Infant and Young Child Feeding. Geneva: 2007.
15. Wamani H, Astrøm AN, Peterson S, Tylleskär T, Tumwine JK. Infant and young child feeding in western Uganda: knowledge, practices and socio-economic correlates. J Trop Pediatr. 2005; 51(6):356-61. doi: 10.1093/tropej/fmi048.

16. Yenit MK, Genetu H, Tariku A. Infant feeding counseling and knowledge are the key determinants of prelacteal feeding among HIV exposed infants attending public hospitals in Ethiopia. Arch Public Health. 2017;75:23. doi:10.1186/s13690-017-0191-y

17. Berde AS, Yalcin SS, Ozcebe H, Uner S, Caman OK. Determinants of pre-lacteal feeding practices in urban and rural Nigeria; a populationbased cross-sectional study using the 2013 Nigeria demographic and health survey data. Afri Health Sci. 2017;17(3):690-9. doi:10.4314/ahs. v17i3.11

18. Gualu T, Dilie A, Haile D, Abate A. Determinants of prelacteal feeding practice among postpartum mothers in Debre Markos town, Amhara regional state, Ethiopia, 2016. Nutr Diet Suppl. 2017;9:97-102.

19. Bililign N, Kumsa H, Mulugeta M, Sisay Y. Factors associated with prelacteal feeding in North Eastern Ethiopia: A community based crosssectional study. Int Breastfeed. 2016;11:13. doi:10.1186/s13006-0160073-x

20. Engebretsen IMS, Nankabirwa V, Doherty T, Diallo AH, Nankunda J, Fadnes LT et al. Early infant feeding practices in three African countries: the PROMISE-EBF trial promoting exclusive breastfeeding by peer counsellors. Int Breastfeed. 2014;9:19. doi:10.1186/1746-43589-19

21. Chea N, Asefa A. Prelacteal feeding and associated factors among newborns in rural Sidama, south Ethiopia: a community based crosssectional Survey. Int Breastfeed J. 2018;13:7. doi:10.1186/s13006-0180149-x

22. Jimoh AO, Adaji SE, Adelaiye HA, Olorukooba AA, Garba C, Mfuh $\mathrm{AL}$ et al. Factors associated with prelacteal feeding practices in a rural northern Nigerian setting. South African Journal of Clinical Nutrition. 2018;31(2):37-42. doi:10.1080/16070658.2017.1359391

23. Nguyen PH, Keithly SC, Nguyen NT, Nguyen TT, Tran LM, Hajeebhoy N. Prelacteal feeding practices in Vietnam: challenges and associated factors. BMC Public Health. 2013;13(1):932. doi:10.1186/1471-2458-13-932Xx

24. Parashar A, Sharma D, Gupta A, Dhadwal DS. Pre-lacteal feeding practices and associated factors in Himachal Pradesh. Int J Health Allied Sci. 2017;6:30-34. doi:10.4103/2278-344X.200205

25. Dawal S, Inamdar IF, Saleem T, Priyanka S, Doibale MK. Study of pre lacteal feeding practices and its determinants in a rural area of Maharashtra. Sch. J. App. Med. Sci. 2014;2(4D):1422-7.

26. Khanal V, Lee AH, da Cruz JLNB, Karkee R. Prelacteal feeding of newborns in postconflict Timor-Leste. J Pediatr Gastroenterol Nutr. 2014;59(2):162-6. doi:10.1097/MPG.0000000000000429

27. National Statistical Office (NSO) and ICF Macro. Malawi Demographic and Health Survey 2010. Zomba, Malawi, and Calverton, Maryland, USA: NSO and ICF Macro: 2011.

28. Whitford HM, Wallis SK, Dowswell T, West HM, Renfrew MJ. Breastfeeding education and support for women with twins or higher order multiples. Cochrane Database of Systematic Reviews. 2017; Issue 2. Art. No.: CD012003. 